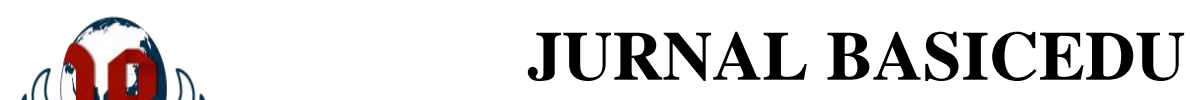

Volume 5 Nomor 3 Tahun 2021 Halaman 1435 - 1443

Research \& Learning in Elementary Education https://jbasic.org/index.php/basicedu

\title{
Pengaruh Model RADEC pada Pembelajaran Tematik terhadap Hasil Belajar Peserta Didik Sekolah Dasar
}

\author{
Selfi Rahmi Andini ${ }^{1 凶}$, Yanti Fitria ${ }^{2}$ \\ Pendidikan Guru Sekolah Dasar, Universitas Negeri Padang, Indonesia ${ }^{1,2}$ \\ E-mail: selfirahmiandini1077@gmail.com ${ }^{1}$, yanti_fitria@fip.unp.ac.id ${ }^{2}$
}

\begin{abstract}
Abstrak
Penelitian ini memiliki tujuan yaitu mendeskripsikan pengaruh di model pembelajaran $R A D E C$ terhadap hasil perolehan belajar peserta didik sekolah dasar pada tema lingkungan sahabat kita. Penelitian ini jenisnya ialah kuantitatif dalam bentuk quasy eksperiment design. Desain yang diterapkan ialah The Non equivalent Control Group Design. Teknik yang diambil untuk pengambilan sampel ialah cluster random sampling, Populasi sebanyak 7 SD dalam lingkup Gugus II Kec. Tanjung Raya. Penelitian dilakukan di SDN 01 Maninjau kelas $\mathrm{V}_{\mathrm{a}}$ beranggota 19 peserta didik untuk kelas eksperimen dan kelas $\mathrm{V}_{\mathrm{b}}$ untuk kelas kontrolnya yang beranggotakan 20 peserta didik. Teknik analisis data yang digunakan ialah menggunakan uji prasyarat berupa uji normalitasnya kemudian uji homogenitasnya serta uji hipotesisnya menggunakan uji t. Rata-rata pada pretest di kelas eksperimen ialah 44,05263, setelah menerapkan model pembelajaran RADEC diperoleh post-test 82,47 . Pada kelas kontrol memperoleh rata-ratanya di pretest 44,15 dan post-test setelah dibelajarkan menggunakan pendekatan konvensional 69,5. Setelah dilakukan uji-t diperoleh $t_{\text {hitung }}=3,68$ dan $t_{\text {tabel }} 1,68709$ dengan taraf nyata 0,05 . Dengan demikian $t_{\text {hitung }}=3,68>t_{\text {tabel }}=1,68709$ maka disimpulkan ditemukan pengaruh model $R A D E C$ terhadap hasil perolehan belajar peserta didik SD tema lingkungan sahabat kita.
\end{abstract}

Kata Kunci: RADEC, Hasil belajar, Tematik Terpadu.

\begin{abstract}
This research is aimed at explaining the impact of the RADEC models on the elementary school students' learning outcomes on the topic 'environment is our best friends'. This research is in a quantitative form with quasy experimental design. The design used is The Non Equivalent Control Group Design. The sampling technique was cluster random sampling with the population consisted of 7 SD in Cluster II Kec. Tanjung Raya. The research was conducted at SDN 01 Maninjau, class VA as an experimental class totaled 19 students and VB as a control class totaled 20 students. The data analysis technique used in this study was preconditioned tests in the form of normality, homogeneity test and hypothetical test using t-test. Pre-test average for the experimental class was 44.05263 and after implementing the RADEC learning models, the post-test was 82.47. Meanwhile, for the control class, it was obtained an average of 44.15 pretest and posttest after being taught using the conventional approach 69.5. After the t-test was carried out, it was acquired $t_{\text {count }}=3.68$ and t table 1.68709 with a significant level of 0.05 . This $t_{\text {count }}=3.68>t_{\text {table }}=1,68709$, it can be concluded, there is effect of the RADEC model on students' learning outcomes on the topic 'environment is our best friends'.
\end{abstract}

Keywords: RADEC, Learning Outcomes, Integrated Thematic Learning.

Copyright (c) 2021 Selfi Rahmi Andini, Yanti Fitria

Corresponding author :

Email : selfirahmiandini1077@gmail.com

DOI : https://doi.org/10.31004/basicedu.v5i3.960

ISSN 2580-3735 (Media Cetak)

ISSN 2580-1147 (Media Online)

Jurnal Basicedu Vol 5 No 3 Tahun 2021

p-ISSN 2580-3735 e-ISSN 2580-1147 


\section{PENDAHULUAN}

Kurikulum 2013 ialah kurikulum dengan memprioritaskan pemahaman, keterampilan, pendidikan karakter. Pada prinsipnya kurikulum ini harus tertuju pada peserta didik, mewajibkan peserta didik ikut serta pada pembelajaran dengan aktif termasuk dirinya sendiri ataupun kelompok, serta mampu membangun pemahaman dan pengetahuannya sendiri. Hal inilah yang menjadi alasan penerapan kurikulum 2013 yang dapat berdampak positif terhadap hasil belajar dan membawa perubahan pada peserta didik dalam hal pengetahuan, sikap dan keterampilan. Perubahan kurikulum saat ini diharapkan dapat menghasilkan individu yang kreatif dan produktif. Kurikulum ini memiliki tujuan untuk membuat peserta didik agar memperoleh potensinya menjadi inovatif serta bisa berpartisipasi dalam lingkungan bermasyarakat, berbangsa, bernegara (Widyastono, 2015). Untuk mencapai tujuan tersebut, maka dapat dicapai dengan menggunakan pembelajaran inovatif yang artinya suatu konsep pembelajaran terbaru, agar dapat memberikan partisipasi kepada siswa dalam membangun serta mengembangkan pengetahuan yang mengarah pada perubahan yang lebih efektif. Model pembelajaran yaitu model yang digunakan agar proses belajar bisa berlangsung (Fauza \& Fitria, 2020). Model pembelajaran dapat meraih hasil perolehan belajar secara signifikan dengan penerapan model tematik terpadu (Wanelly \& Fitria, 2019). Model RADEC ialah salah satu model inovatif menuntut peserta didik menumbuhkan keahlian untuk zaman modern serta konsep materi yang dipelajari terkuasai oleh perserta didik. Menurut Sopandi dalam (Pratama, Sopandi, \& Hidayah, 2019) juga mengemukakan bahwa model ini ialah model dalam pembelajaran untuk membuat individu agar mempunyai keterampilan tinggi, keaktifan peserta didik untuk belajar mandiri, menumbuhkan keahlian dalam berkomunikasi, berkolaborasi, juga menunjang peserta didik memperoleh pemahaman materi. Model pembelajaran ini memiliki tahapan yang dalam proses pelaksanaanya tidak memakan waktu. Menurut Fitria (2018) bahwa di sekolah dasar peserta didik harus disiapkan agar dapat belajar mandiri supaya bisa menumbuhkan potensinya, guru diwajibkan agar bisa membuat peserta didik menjadi belajar secara mandiri dan membagikan contoh yang positif pada saat proses belajar sedang berlangsung.

Model yang digunakan untuk pembelajaran memiliki kelebihan masing-masing, termasuk juga model yang digunakan peneliti dalam proses pembelajaran yaitu model RADEC. Menurut Sopandi (Sopandi \& Handayani, 2019) Model RADEC mampu membuat peserta didik untuk rajin membaca, meningkatkan pemahaman materi dan memotivasi mereka untuk mengantongi kompetensi yang dituntut pada zaman sekarang. Model RADEC memiliki keunggulan, diantaranya yaitu (1) memberikan kesempatan kepada guru untuk mendesain model yang digunakan agar proses pembelajaran menjadi menarik, (2) meningkatkan kinerja berpikir kritis pada peserta didik, (3) meningkatkan kemampuan menganalisis dan membaca siswa, (4) meningkatkan kerjasama dalam kelompok (Kaharuddin, 2020). Sejalan dengan pendapat (Y. Fitria, 2018a) model pembelajaran yang akurat akan membuat tercapainya tujuan pembelajaran sesusai dengan yang telah dirancang. Model pada pembelajaran yang akurat diterapkan untuk proes pembelajaran tematik terpadu K13 selain model RADEC yaitu pembalajaran dengan model $P B L$ dan $P J B L$ (Friani, Sulaiman, \& Mislinawati, 2017).

Untuk memperkuat penjelasan di atas dapat dibuktikan dari penelitian terdahulu yaitu penelitian yang dilakuan oleh Nurseptiani \& Maryani, (2019) melalukan penelitian yang berjudul "Meningkatkan Minat Belajar Bahasa Indonesia dengan Membandingkan Model Pembelajaran RADEC dan Model Pembelajaran Konvensional di Kelas V SD Negeri Sukamaju" terdapat perbedaan peningkatan minat belajar bahasa Indonesia peserta didik pada kelas eksperimen dan kelas kontrol di SD Negeri Sukamaju. Perbedaan antara penelitian yang dilakukan oleh Nurseptiani dengan yang dilakukan penelti adalah meneliti hasil belajar peserta didik pada pembelajaran tematik di kelas V Sekolah Dasar.

Pengamatan dilakukan oleh peneliti di Sekolah Dasar 01 Maninjau Kecamatan Tanjung Raya pada PBM berbasis tematik terpadu di tema enam subtema dua pembelajaran 3, 4, 5, dan 6 peneliti menemukan 
1437 Pengaruh Model RADEC pada Pembelajaran Tematik terhadap Hasil Belajar Peserta Didik Sekolah Dasar - Selfi Rahmi Andini, Yanti Fitria

DOI: https://doi.org/10.31004/basicedu.v5i3.960

bahwa pada saat proses belajar yang titik fokus yang seharusnya kepada peserta didik kurang terlihat (student center), model pembelajaran yang diterapkan masih memakai pendekatan konvensional, peserta didik pasif dan aktivitas yang dilakukannya hanya mencatat sehingga peluang peserta didik aktif untuk menambah pengetahuannya menjadi tidak efisien. Peserta didik pasif bertanya pada guru jika ia mendapat masalah dalam materi yang diberikan dan membuat perolehan belajarnya menjadi rendah. dengan pembelajaran tematik terpadu dalam proses pembelajarannya dapat mendorong peserta didik menyusun informasi, memproses informasi tersebut dan meningkatkan kemampuan peserta didik dalam aspek belajarnya (Y. Fitria, 2018).

Pemicu hasil perolehan belajar peserta didik yang kecil yaitu pengaplikasian model penataran yang diterapkan (Kurniawan, Elmunsyah, \& Muladi, 2018). Belajar melibatkan terjadinya proses mental, menyentuh perasaan, mengalami dan berpikir yang aktif (Y. \& I. W. Fitria, 2020). Dalam prosesnya, ketika individu belajar maka ia akan merasakan perubahan perilaku dan menampilkan hasil belajar sebagai tolak ukur bahwa ia mengerti pelajaran yang telah diterimanya. Oleh sebab itu, model pembelajaran yang efektif diperlukan untuk menjawab permasalahan yang telah peneliti uraikan. Berdasarkan uraian tersebut tujuan penelitian ialah menguraikan "Pengaruh Model RADEC pada Pembelajaran Tematik terhadap Hasil Belajar Peserta Didik Sekolah Dasar”.

\section{METODE}

Penelitian yang dilaksanakan merupakan penelitian kuantitatif, metode penelitian eksperimen menggunakan quasi experimental design. Rancangan diterapkan pada penelitian ini ialah rancangan penelitian menurut Sugiyono (2015) Nonequivalent Control Group Design. Desain pada penelitian terbagi menjadi 2 grup kelompok, yakni grup eksperimen, grup kontrol. Grup eksperimen dan grup kontrol awalnya diserahkan pretest $\left(\mathrm{O}_{1}, \mathrm{O}_{3}\right)$ sebagai pondasi dalam menentukan perubahan. Lalu, kelompok eksperimen diajarkan dengan RADEC (X), sedangkan kelompok kontrol menggunakan model konvensional (-). Kemudian, kedua kelompok diberikan post-test $\left(\mathrm{O}_{2}, \mathrm{O}_{4}\right)$ pada masing-masing kelompok untuk menunjukkan seberapa jauh akibat perlakuan. Terakhir, hasil yang diperoleh dibandingkan untuk melihat adanya pengaruh yang didapatkan dari model di eksperimen, sehingga bisa diketahui pengaruh di kelas eksperimen.

Populasi dalam penelitian ialah 7 SD yang terdapat dalam gugus II Kecamatan Tanjung Raya. Sampel penelitian ialah seluruh peserta didik SD Kelas VA untuk kelompok eksperimen dengan anggota 19 orang, dan peserta didik Kelas VB dengan anggota 20 orang sebagai kelas kontrol pada SDN 01 Maninjau. Instrumen dalam penelitian ialah lembar pertanyaan pretest dan posttest yang berguna untuk melihat sejauh mana pengaruh dari model $R A D E C$ terhadap perolehan belajar yang didapat peserta didik pada tema lingkungan sahabat kita. Teknik dalam pengumpulan perolehan data penelitian ialah teknik tes. Pengumpulan perolehan data dengan teknik tes yaitu menjawab instrumen tes agar mendapat data terhadap penguasaan peserta didik terlebih dalam bagian pengetahuan (Lestari \& Yudhanegara, 2017).

Analisis perolehan data yang diterapkan ialah t-test yang diterapkan jika prasyarat analisis t-test terpenuhi. Uji yang digunakan untuk prasyarat di analisis data ialah uji normalitasnya serta uji homogenitas varians. Uji normalitas menerapkan rumus uji Kolmogorov - Smirnov. Data bisa disebut normal apabila harga $\mathrm{D}_{0}<\mathrm{D}_{\text {tabel. }}$ sedangkan tujuan uji di homogenitas ialah untuk mengetahui kelompok tersebut kelompok homogen. Uji homogenitas variansi populasi digunakan agar kelompok data diuji dengan uji Bartlett.

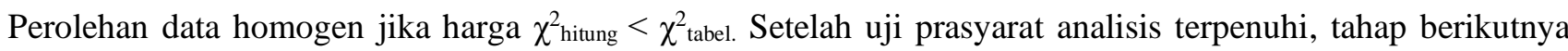
ialah uji hipotesis menggunakan analisis statistika uji t. Lalu dilakukan uji N-Gain yang berguna agar dapat mendapati peningkatan hasil perolehan belajar peserta didik pada sebelum kemudian setelah belajarnya. 
1438 Pengaruh Model RADEC pada Pembelajaran Tematik terhadap Hasil Belajar Peserta Didik Sekolah Dasar - Selfi Rahmi Andini, Yanti Fitria

DOI: https://doi.org/10.31004/basicedu.v5i3.960

\section{HASIL DAN PEMBAHASAN}

Penelitian atau riset ini memiliki perolehan hasil di SDN 01 Maninjau,yaitu adanya perbedaan pada hasil perolehan belajarnya peserta didik di kelas grup eksperimen dengan model $R A D E C$ dengan hasil belajarnya peserta didik kelas grup kontrol dengan mengimplementasikan pembelajaran konvensional. Dari uji-t yang dilakukan didapat nilai $\mathrm{t}_{\mathrm{hitung}}=3,68$ di taraf signifikansi 0,05 , kemudian dk yaitu $=\mathrm{n}_{1}+\mathrm{n}_{2}-2=19$ $+20-2=37$, diperoleh $t_{\text {tabel }}=1,68709$. didapat $\mathrm{H}_{\mathrm{a}}$ diterima sedangkan $\mathrm{H}_{\mathrm{o}}$ ditolak. Kesimpulan hipotesis (dugaan) pada riset ini ialah adanya pengaruh yang signifikan model $R A D E C$ pada hasil perolehan belajar pembelajaran tematik terpadu kelas V SDN 01 Maninjau Kec. Tanjung Raya.

Pengumpulan data dalam riset ini ialah dengan melaksanakan pretest pada 2 kelas sampel supaya memperoleh data gambaran (awal) tentang penguasaan peserta didik terkait materi pada tema delapan subtema satu pembelajaran tiga, dan empat. Jumlah soal yang harus dijawab siswa sebanyak 30 soal berbentuk objektif. Lalu, diberikan perlakukan model $R A D E C$ di sampel eksperimen dan pembelajaran menggunakan konfensional di sampel kontrol, dilanjutkan dengan pelaksanaan posttest perolehan belajar peserta didik setelah pemberian perlakuan di masing-masing kelompok.

Dari analisis data di pretest dan di posttest, perolehan belajar pada kategori eksperimen dan kategori kontrol, adanya nilai yang berbeda dari perolehan nilai di masing-masing kelas. Sampel eksperimen diperoleh rata-rata pretest yaitu 44,05263, standard deviasi ialah 11,36991 nilai variansnya 129,2749 nilai tertinggi 63 dan nilai terendahnya 27. Sementara itu, rata-rata pre-test grup kontrol adalah 44,15, standar deviasi 12,29152 , varians 151,0816 , perolehan belajar tertinggi 67 dan perolehan belajar terendah 27. Rata-rata nilai post-test kelompok eksperimen ialah 82,47 standar deviasi 11,60157, varians 134,5965, nilai yang tertinggi 97 dan nilai yang terendah 60. Rata-rata post-test kelas kontrol ialah 69,5 standar deviasi 10,72626, varians 115,0526 , nilai yang tertinggi 90 dan nilai yag terendah 53. Peningkatan pada hasil perolehan belajar peserta didik di sampel eksperimen signifikan dibandingkan sampel kontrol. Lebih jelasnya perbandingan pretest posttest grup eksperimen terhadap grup kontrol dapat dilihat dibawah ini:

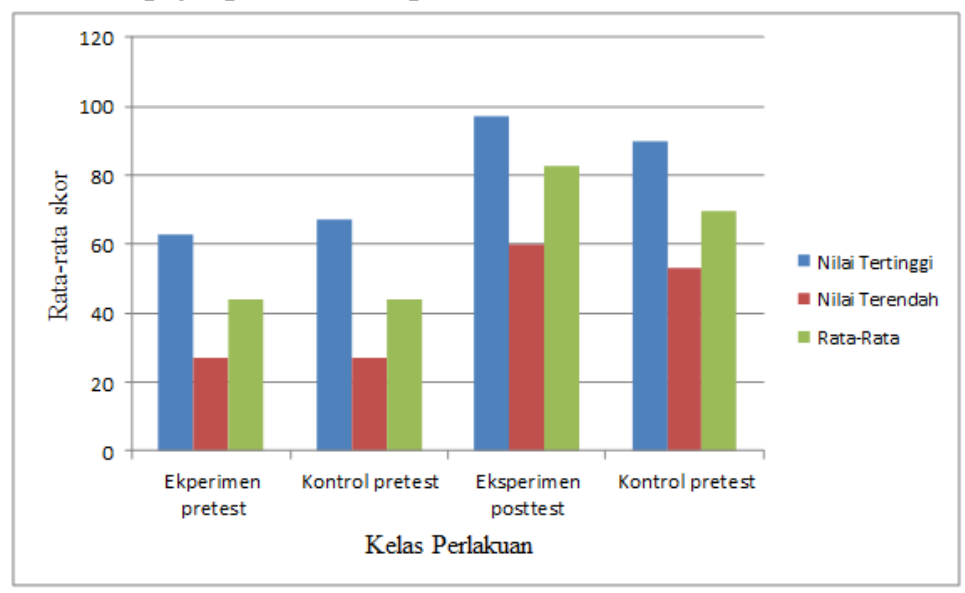

Gambar 1. Grafik perbandingan hasil pretest, posttest kelas eksperimen \& kelas kontrol

Sebelum menerapkan uji hipotesis, dilakukan uji normalitasnya dan uji homogenitasnya. Uji normalitas untuk datanya di pretest, posttest ke 2 sampel menerapkan uji rumus Kolmogorof-Smirnov. Uji KolmogorofSmirnov yang telah dilakukan pada nilai pretest dan posttest sampel eksperimen (VA) terhadap sampel kontrol (VB) diperoleh nilai $\mathrm{D}_{0}<\mathrm{D}_{\text {Tabel }}$ maka data normal. Lalu, dilakukan uji homogenitas yang digunakan ialah uji Bartlett. Di pre-test kelompok eksperimen, kontrol di dapatkan $\mathrm{F}_{\text {hitung }}<\mathrm{F}_{\text {tabel }}$ yaitu 1,731<2,2171 maka pretest mempunyai variansi yang homogen (sama). Untuk posttest grup eksperimen dan grup kontrol memperoleh $\chi^{2}$ hitung $<\chi_{\text {tabel }}^{2}=0,113807<3,841$ maka, posttest memiliki variansi homogen (sama). Berdasarkan uji di homogenitas ke 2 kelompok kelas bisa dirangkum perolehan data pre-test, post-test terdapat variansi yang homogen di taraf nyata $5 \%$. 
Setelah didapat data pos-test peserta didik kedua kelompok sampel berdistribusi dengan normal juga mempunyai variansi homogen (sama). Kemudian dilakukan menguji hipotesis menggunakan rumus uji - $\mathrm{t}$ yaitu :

$$
\mathrm{t}=\frac{\bar{x} 1-\bar{x} 2}{\sqrt{\frac{(n 1-1) s 1^{2}+(n 2-1) s 2^{2}}{n 1+n 2-2}\left(\frac{1}{n 1}+\frac{1}{n 2}\right)}}
$$

Setelah dilakukan perhitungan diperoleh nilai $\mathrm{t}_{\text {hitung }}=3,68$ taraf signifikansinya 0,05 kemudian $\mathrm{dk}=\mathrm{n}_{1}$ $+\mathrm{n}_{2}-2=19+20-2=37$, diperoleh $\mathrm{t}_{\text {tabel }}=1$,68709. Diperoleh $\mathrm{t}_{\text {hitung }}>\mathrm{t}_{\text {tabel, }}$, maka $\mathrm{H}_{0}$ ditolak kemudian $\mathrm{H}_{\mathrm{a}}$ diterima. Kesimpulannya terdapat adanya pengaruh positif model $R A D E C$ pada hasil belajar di pembelajaran tematik kelas V SD Gugus/Himpunan II Kec. Tanjung Raya.Untuk menaksir kenaikan hasil perolehan belajar pada peserta didik sebelum dan sesudah dilaksanakan pembelajaran, diberikan uji N-Gain. Uji N-Gain diperoleh data untuk kelas eksperimen adanya 11 peserta didik dengan perolehan kriteria nilai $\mathrm{N}$-Gain tinggi dan 8 peserta didik perolehan kriteria nilai N-Gain sedang. Di kelas kontrol adanya 20 peserta didik dengan perolehan nilai $\mathrm{N}$-Gain sedang.

Pembelajaran tematik terpadu memiliki beberapa karakteristik. Karakteristik dari pembelajaran tematik terpadu yaitu menjadikan peserta didik sebagai pusat pembelajaran, pembelajarannya mengaitkan beberapa mata pelajaran yang digabungkan dengan konsep yang sama, tidak jelas pemisah antar mata pelajaran, pembelajarannya tidak kaku dan menyenangkan (Rusman, 2015). Karakteristik peserta didik dalam belajar merupakan anak-anak yang aktif, konstruktif, memecahkan masalah, menghasilkan hipotesis dan mengetesnya (Y. Fitria, 2018a). Hipotesis mereka ambil dari hasil dalam proses belajar dan mengetesnya berdasarkan hipotesis mereka tersebut. Keterpaduan antara karakteristik peserta didik dengan karakteristik pembelajaran tematik terpadu akan membuat hasil belajar mereka menjadi lebih baik. Pada penelitian ini peneliti memfokuskan hasil belajar pada aspek pengetahuan peserta didik pembelajaran tematik tema 8 subtema 1 pembelajaran 3 dan 4 di kelas V SD N 01 Maninjau Kecamata Tanjung Raya, alasannya agar penelitian yang dilakukan memiliki arah yang jelas pada aspek yang diteliti.

Penelitian dilaksanakan pada proses belajar di kelompok sampel yaitu kategori eksperimen dan kontrol. Penerimaan pembelajaran yang digunakan di kelas grup eksperimen dengan model RADEC. Pendekatan di pembelajaran diterapkan oleh pendidik berfungsi supaya meningkatkan keterampilan dalam berpikir yang kritis (Pratama, Y., A., Sopandi., W \& Hidayah, 2019). Menurut Sopandi dalam (Sopandi \& Handayani, 2019) RADEC dianjurkan diterapkan pada sekolah dasar, sebab model ini dapat dipahami dengan mudah implementasinya, membuat peserta didik mendapatkan tingkah laku, pengetahuan, berbagai abad ke-21 keterampilannya (berpikir dengan kritis, solusi dari permasalahan, kolaborasi, hubungan dan kreatif).

Peserta didik diajak aktif, kritis, memiliki penangkapan konseptual terhadap materi pembelajaran. hal ini sesuai dengan pendapat Sopandi dalam (Sopandi \& Handayani, 2019) mendorong peserta didik agar aktif, berpikir kritis di pembelajaran, berpendapat dengan kreatif, memberikan kesempatan peserta didik agar mempelajari materi melalui tugas pra pembelajaran. Pelaksanaan model RADEC dalam pembelajaran menerapkan lima langkah yang dikemukakan oleh Kaharuddin (2020) RADEC yaitu: (1) Read, peserta didik membaca pada buku yang sesuai dengan pelajaran yang akan dilangsungkan di kelas, (2) Answer, peserta didik menanggapi pertanyaan pra pembelajaran sebelum proses pembelajaran didalam kelas. Kegiatan ini diterapkan secara mandiri dirumah. Tahap ini juga guru dapat mengetahui konsep yang kurang dipahami pada peserta didik kemudian dapat dibahas dengan peserta didik di dalam kelas bersama-sama, (3) Discuss, peserta didik belajar membuat kelompok dua sampai empat individu agar merundingkan jawaban prapembelajaran, guru bisa mengenali apa saja kebutuhan siswa, (4) Explain, menyajikan materi yang telah didiskusikan, narasumber ditunjuk dari perwakilan mereka, (5) Create, peserta didik menghasilkan ide yang kreatif seperti rumusan pada pertanyaan penyelidikan, atau pemecahan/solusi masalah. Ide kreatifnya berkaitan dengan materi yang telah dikuasai.

Pada zaman sekarang, perkembangan terhadap apapun sangat pesat, termasuk dalam bidang 
pengetahuan, contohnya banyak model-model pembelajaran terbaru yang dikembangkan oleh para ahli seperti model RADEC ini. Dampak dibidang pengetahuan dapat mendorong perubahan mengajar dari yang hanya mengingat fakta yang dilakukan dengan ceramah berubah menjadi dorongan kemampuan berpikir yang kritis (Y. Fitria, 2017). Salah satu jalan keluarnya ialah menerapkan pembelajaran tematik terpadu. Menurut Fitria (2019) pembelajaran tematik ialah pembelajaran pada tema yang menghubungkan beberapa mata pelajaran yang membagikan pengetahuan belajar bermanfaat untuk peserta didik SD. Dalam proses belajar, perlu mempertimbangkan prinsip serta tercapainya tujuan yang dirancang dalam proses pembelajaran tersebut untuk memperbarui pengetahuan terhadap siswa (Y. \& I. W. Fitria, 2020). Belajar melibatkan terjadinya proses mental, menyentuh perasaan, mengalami dan berpikir yang aktif (Y. \& I. W. Fitria, 2020). Dalam prosesnya, ketika individu belajar maka ia akan merasakan perubahan perilaku dan menampilkan hasil belajar sebagai tolak ukur bahwa ia mampu memahami pelajaran yang diterimanya.

Pembelajaran dikelas kontrol yang menggunakan pembelajaran konvensional menciptakan suasana belajar siswa yang tergolong pasif, terlihat pada saat pembelajaran guru yang lebih aktif karena siswa hanya mendengarkan materi yang diterangkan guru. Selama PBM kurangnya hubungan guru terhadap peserta didik yang menjadikan peserta didik tidak tertarik kepada guru karena mereka sibuk dengan dirinya sendiri maupun teman sebangkunya. Peserta didik pasif, kemudian mereka hanya mendapatkan pengetahuan dari guru yang mengajar tersebut (Hasnan, Rusdinal, \& Fitria, 2020).Pembelajaran di kelas kontrol yang menerapkan pembelajaran konfensional menjadikan peserta didik pasif. Peserta didik di kelompok kontrol kurang aktif dari pada peserta didik di kelompok eksperimen di belajar yang sedang berlangsung, menjadikan adanya dampak belajar yang membuat hasilnya di kelas grup kontrol lebih kecil dari pada hasil perolehan belajar peserta didik kelas group eksperimen.

Dari pengolahan data hasil pretest pada kelas eksperimen diperoleh data pada penelitian pada tabel 1.

Tabel 1 Rekapitulasi Data Hasil Pretest Kelas Eksperimen dan Kelas Kontrol

\begin{tabular}{|c|c|c|}
\hline \multirow{2}{*}{ Variabel } & \multicolumn{2}{|c|}{ Pretest } \\
\cline { 2 - 3 } & Kelas Eksperimen & Kelas Kontrol \\
\hline $\mathrm{N}$ & 19 & 20 \\
\hline Nilai Tertinggi & 63 & 67 \\
\hline Nilai terendah & 27 & 27 \\
\hline Mean/Rata-rata & 44,05263 & 44,15 \\
\hline Standar Deviasi & 11,36991 & 12,29152 \\
\hline Varians & 129,2749 & 151,0816 \\
\hline
\end{tabular}

Berdasarkan tabel 1. diatas, di kelas eksperimen dengan jumlah peserta didik 19 orang memperoleh nilai tertinggi 63 dan nilai terendah 27. Dari nilai kelas eksperimen diperoleh rata-rata nilai sebesar 44,05263, standar deviasi 11,36991 dan nilai varians 129,2749. Sedangkan kelas kontrol dengan jumlah anak 20 orang memperoleh nilai tertinggi 67 dan nilai terendah 27. Dari nilai kelas kontrol diperoleh rata-rata nilai sebesar 44,15, standar deviasi 12,29152 dan nilai varians 151,0816. Kemudian, dari pengolahan data hasil posttest pada kelas kontrol diperoleh data pada penelitian pada tabel 2 berikut:

Tabel 2. Rekapitulasi Data Hasil Posttest Kelas Eksperimen dan Kelas Kontrol

\begin{tabular}{|c|c|c|}
\hline \multirow{2}{*}{ Variabel } & \multicolumn{2}{|c|}{ Pretest } \\
\cline { 2 - 3 } & Kelas Eksperimen & Kelas Kontrol \\
\hline $\mathrm{N}$ & 19 & 20 \\
\hline Nilai Tertinggi & 97 & 90 \\
\hline Nilai terendah & 60 & 53 \\
\hline Mean/Rata-rata & 82,47 & 69,5 \\
\hline Standar Deviasi & 11,60157 & 10,72626 \\
\hline Varians & 134,5965 & 115,0526 \\
\hline
\end{tabular}


1441 Pengaruh Model RADEC pada Pembelajaran Tematik terhadap Hasil Belajar Peserta Didik Sekolah Dasar - Selfi Rahmi Andini, Yanti Fitria

DOI: https://doi.org/10.31004/basicedu.v5i3.960

Berdasarkan tabel 2 diatas, di kelas eksperimen dengan jumlah peserta didik 19 orang memperoleh nilai tertinggi 97 dan nilai terendah 60. Dari nilai kelas eksperimen diperoleh rata-rata nilai sebesar 82,47 standar deviasi 11,60157 dan nilai varians 134,5965. Sedangkan kelas kontrol dengan jumlah anak 20 orang memperoleh nilai tertinggi 90 dan nilai terendah 53. Dari nilai kelas kontrol diperoleh rata-rata nilai sebesar 69,5, standar deviasi 10,72626 dan nilai varians 115,0526 .

Uji normalitas bertujuan untuk melihat data hasil belajar dari kedua kelas sampel berdistribusi normal atau tidak. Sehingga dapat digunakan analisis dengan menggunakan t-test. Data yang digunakan untuk uji normalitas ini adalah nilai pretest dan posttest pada kelas eksperimen dan kelas kontrol. Untuk menghitung uji normalitas menggunakan uji Kolmogorov-Smirnov. Setelah dilakukan perhitungan normalitas dara dnegan uji Kolmogorov-Smirnov pada kedua kelas sampel, maka diperoleh harga Do dan Dt dengan taraf nyata 0,05 seperti yang tertera pada tabel 3. dibawah ini.

Tabel 3. Hasil Perhitungan Uji Normalitas dengan Kolmogorov- (Pretest)

\begin{tabular}{|c|c|c|c|c|c|c|}
\hline No & Kelas & $\mathrm{N}$ & $\mathrm{A}$ & $\mathrm{D}_{0}$ & $\mathrm{D}_{\text {tabel }}$ & Keterangan \\
\hline 1. & Ekperimen & 19 & 0,05 & 0,165558 & 0,301 & $\mathrm{D}_{0}<\mathrm{D}_{\mathrm{t}}$ (Normal) \\
\hline 2. & Kontrol & 20 & 0,05 & 0,187271 & 0,294 & $\mathrm{D}_{0}<\mathrm{D}_{\mathrm{t}}$ (Normal) \\
\hline
\end{tabular}

Dari tabel 3. diperoleh bahwa untuk kedua kelas sampel harga $\mathrm{D}_{0}<\mathrm{D}_{\text {tabel. }}$. Hal ini berarti data berdistribusi normal. Sedangkan untuk posttest dapat dilihat pada tabel 4. sebagai berikut:

Tabel 4. Hasil Perhitungan Uji Normalitas dengan Kolmogorov-Smirnov (Posttest)

\begin{tabular}{|c|c|c|c|c|c|c|}
\hline No & Kelas & $\mathrm{N}$ & $\mathrm{A}$ & $\mathrm{D}_{0}$ & $\mathrm{D}_{\text {tabel }}$ & Keterangan \\
\hline 1. & Ekperimen & 19 & 0,05 & 0,129488 & 0,301 & $\mathrm{D}_{0}<\mathrm{D}_{\mathrm{t}}($ Normal $)$ \\
\hline 2. & Kontrol & 20 & 0,05 & 0,02799 & 0,294 & $\mathrm{D}_{0}<\mathrm{D}_{\mathrm{t}}($ Normal $)$ \\
\hline
\end{tabular}

Dari tabel 4. terlihat bahwa perhitungan uji normalitas kelas eksperimen dengan nilai $\mathrm{D}_{\text {hitung }} 0,129488$ lebih kecil dari $\mathrm{D}_{\text {tabel }} 0,301$ untuk taraf 0,05 . Sedangkan untuk kelas kontrol, diperoleh nilai $\mathrm{D}_{\text {hitung }} 0,02799$ lebih kecil dari $D_{\text {tabel }} 0,294$ untuk taraf 0,05 . Berdasarkan data tersebut dapat disimpulkan bahwa untuk posttest kelas eksperimen dan kelas kontrol berasal dari data yang berdistribusi normal.

Pengujian prasyarat kedua adalah pengujian homogenitas dengan menggunakan Uji Bartlett. Pengujian ini bertujuan untuk data hasil belajar dari kedua kelas sampel mempunyai variansi yang homogen atau tidak. Perhitungan harga $\chi^{2}$ dengan taraf nyata $\alpha=0,05$ dari tabel Chi Kuadrat $\left(\chi^{2}\right)$. Hasil perhitungan uji homogenitas dapat dilihat pada tabel 5 dibawah ini:

Tabel 5. Hasil Perhitungan Uji Homogenitas dengan Bartlett (Pretest)

\begin{tabular}{|c|c|c|c|c|c|}
\hline No & Kelas & $\alpha$ & $\chi^{2}$ hitung & $\chi^{2}$ tabel & Keterangan \\
\hline 1. & Ekperimen & 0,05 & 0,112027 & 3,841 & Homogen \\
\cline { 1 - 2 } 2. & Kontrol & & & & \\
\hline
\end{tabular}

Dari tabel 5. diatas, dapat disimpulkan bahwa hasil perhitungan kedua kelas pada Prettest didapatkan hasil $\chi^{2}$ hitung $<\chi_{\text {tabel }}^{2}$ maka data homogen. Sedangkan untuk Posttest dapat dilihat pada tabel 6. dibawah ini:

Tabel 6. Hasil Perhitungan Uji Homogenitas dengan Bartlett (Posttest)

\begin{tabular}{|c|c|c|c|c|c|}
\hline No & Kelas & $\alpha$ & $\chi^{2}$ hitung & $\chi^{2}$ tabel & Keterangan \\
\hline 1. & Ekperimen & 0,05 & 0,113807 & 3,841 & Homogen \\
\cline { 1 - 2 } 2. & Kontrol & & & & \\
\hline
\end{tabular}

Berdasarkan tabel 6. di atas, dapat disimpulkan bahwa kedua kelompok kelas eksperimen dan kelas kontrol pada Posttest didapatkan hasil memiliki variansi yang homogeny $\chi^{2}{ }_{\text {hitung }}<\chi^{2}$ tabel maka data homogen. Berdasarkan kedua tabel di atas, dapat disimpulkan bahwa kedua kelompok kelas eksperimen dan kelas kontrol memiliki variansi yang homogen. 
1442 Pengaruh Model RADEC pada Pembelajaran Tematik terhadap Hasil Belajar Peserta Didik Sekolah Dasar - Selfi Rahmi Andini, Yanti Fitria

DOI: https://doi.org/10.31004/basicedu.v5i3.960

Berdasarkan hasil uji prasyarat diperoleh bahwa hasil belajar berdistribusi normal dan homogeny, maka dilakukan uji hipotesis dengan Uji t. Hasil uji hipotesis dengan menggunakan $t$-test dapat dilihat pada tabel 7. dibawah ini:

Tabel 7. Hasil Pengujian dengan t-test

\begin{tabular}{|c|c|c|c|c|}
\hline No & Kelompok & Nilai rata-rata kelas & $\mathrm{T}_{\text {hitung }}$ & $\mathrm{T}_{\text {tabel }} 0,05$ \\
\hline 1 & Eksperimen & 82,47 & 3,68 & 1,68709 \\
\hline 2 & Kontrol & 69,5 & & \\
\hline
\end{tabular}

Dilihat pada tabel $\mathrm{t}$ degan $\mathrm{dk}\left(\mathrm{n}_{1}+\mathrm{n}_{2}-2\right)=37$. Maka yang dipedomani pada tabel yaitu dengan $\mathrm{dk} 37$ untuk taraf nyata 0,05 didapat harga $t_{\text {tabel }} 1,68709$. Maka dapat disimpulkan bahwa hasil belajar peserta didik pada pembelajaran tematik terpadu yang menggunakan model $R A D E C$ dalam pembelajaran lebih tinggi dari pada hasil belajar peserta didik pada pembelajaran tematik terpadu dengan pembelajaran konvensional dan terdapat pengaruh terhadap hasil belajar peserta didik pada pembelajaran tematik terpadu antara kelas eksperimen yang menggunakan model $R A D E C$ dibandingkan dengan kelas kontrol dengan pembelajaran konvensional.

Selanjutnya dilakukan Uji $\mathrm{N}$-Gain. Uji $\mathrm{N}$-Gain dilakukan untuk mengetahui adanya peningkatan hasil belajar kognitif peserta didik setelah diberikan perlakukan. Peningkatan ini diambil dari nilai pretest dan posttest yang didapatkan oleh peserta didik.

Tabel 8. Hasil N-Gain Pretest-Posttest pada Kelas Eksperimen dan Kelas Kontrol

\begin{tabular}{|c|c|c|c|c|c|c|}
\hline \multirow{2}{*}{} & \multicolumn{3}{|c|}{ Eksperimen } & \multicolumn{3}{c|}{ Kontrol } \\
\cline { 2 - 7 } & Pretest & Posttest & N-Gain & Pretest & Posttest & $N$-Gain \\
\hline$\Sigma$ & 837 & 1567 & 13,52 & 857 & 1480 & 11,24 \\
\hline $\bar{X}$ & 44,0526 & 82,4737 & 0,71 & 42,85 & 74 & 0,56 \\
\hline
\end{tabular}

Berdasarkan data di atas, dapat dianalisis bahwa selisih antara nilai pretest dan nilai posttest menghasilkan nilai $\mathrm{N}-G$ ain. Untuk kelas eksperimen rata-rata nilai pretest sebesar 44,0526 dan rata-rata nilai posttest sebesar 86,36 dengan perolehan rata-rata $\mathrm{N}$-Gain sebesar 0,78 dan masuk dalam kategori tinggi. Kemudian untuk kelas control rata-rata nilai pretest sebesar 42,85 dan rata-rata nilai posttest sebesar 74 dengan perolehan rata-rata $\mathrm{N}-$ Gain sebesar 0,56 dan masuk dalam kategori sedang. Dapat disimpulkan bahwa kedua kelas ini memiliki perbedaan pada hasil belajar peserta didik pada pembelajaran tematik terpadu.

\section{KESIMPULAN}

Berdasarkan hasil penelitian yang telah dikemukakan dapat disimpulkan model pembelajaran $R A D E C$ dapat mengembangkan potensi peserta didik untuk dipakai pada abad ke-21 (berpikir dengan kritis, solusi dari permasalahan, kolaborasi, hubungan dan kreatif). Kesimpulannya, karena $t_{\text {hitung }}<t_{\text {tabel }}$ maka hipotesis awal ditolak, terdapat pengaruh model pembelajaran $R A D E C$ terhadap hasil pembelajaran peserta didik sekolah dasar, khususnya pada bidang pengetahuannya.

\section{UCAPAN TERIMA KASIH}

Terima kasih untuk Ibu Dr.Yanti Fitria, M.Pd yang meluangkankan waktu untuk arahan pembuatan artikel ini dan seluruh bantuan dari teman-teman yang namuanya tidak bisa disebutkan satu persatu. Tanpa arahan dan bantuan tersebut peneliti tidak dapat menyelesaikan artikel ini.

\section{DAFTAR PUSTAKA}

Fauza, R., \& Fitria, Y. (2020). Pengaruh Model Pembelajaran Problem Based Learning Terhadap Kemampuan Berpikir Kritis di Sekolah Dasar. Jurnal Pendidikan Tambusai, 4(3), 2685-2692.

Fitria, Y. (2017). Efektivitas Capaian Kompetensi Belajar Siswa Dalam Pembelajaran Sains Di Sekolah Dasar. Jurnal Inovasi Pendidikan Dan Pembelajaran Sekolah Dasar, I(2). 
1443 Pengaruh Model RADEC pada Pembelajaran Tematik terhadap Hasil Belajar Peserta Didik Sekolah Dasar - Selfi Rahmi Andini, Yanti Fitria

DOI: https://doi.org/10.31004/basicedu.v5i3.960

https://doi.org/10.24036/jippsd.v1i2.8605

Fitria, Y. (2018a). Landasan Pembelajaran Sains Terintegrasi ( Terpadu ).

Fitria, Y. (2018b). Scientific Literacy as Foundation in Character Building for Early Childhood and Elementary Grade School. 169(Icece 2017), 80-82. https://doi.org/10.2991/icece-17.2018.19

Fitria, Y. \& I. W. (2020). Pengembangan Model Pembelajaran PBL Berbasis Digital Untuk Meningkatkan Karakter Peduli Lingkungan dan Literasi Sains. Yogyakarta: CV Budi Utama.

Friani, I. F., Sulaiman, \& Mislinawati. (2017). Kendala Guru dalam Menerapkan Model Pembelajaran pada Pembelajaran Tematik berdasarkan Kurikulum 2013 di SD Negeri 2 Kota Banda Aceh. Jurnal Ilmiah Pendidikan Guru Sekolah Dasar FKIP Unsyiah, 2, 88-97.

Hasnan, S. M., Rusdinal, R., \& Fitria, Y. (2020). Pengaruh Penggunaan Model Discovery Learning Dan Motivasi Terhadap Kemampuan Berpikir Kritis Peserta Didik Sekolah Dasar. Jurnal Basicedu, 4(2), 239-249. https://doi.org/10.31004/basicedu.v4i2.318

Kaharuddin, A. (2020). Pembelajaran Inovatif \& Variatif. Gowa: CV Berkah Utami.

Kurniawan, H. R., Elmunsyah, H., \& Muladi, M. (2018). Perbandingan Penerapan Model Pembelajaran Project Based Learning (PJBL) dan Think Pair Share (TPS) Berbantuan Modul Ajar Terhadap Kemandirian dan Hasil Belajar Rancang Bangun Jaringan. Jurnal Pendidikan (Teori Dan Praktik), 3(2), 80. https://doi.org/10.26740/jp.v3n2.p80-85

Lestari, kurnia E., \& Yudhanegara, M. R. (2017). Penelitian Pendidikan Matematika. Bandung: PT Refika Aditama.

Nurseptiani, K., \& Maryani, N. (2019). Meningkatkan Minat Belajar Bahasa Indonesia dengan Membandingkan Model Pembelajaran Radec dan Model Pembelajaran Konvensional (Penelitian Eksperimen di SD Negeri Sukamaju Tahun Pelajaran 2019 / 2020). Jurnal Pendidikan Guru Madrasah Ibtidaiyah, 2(2), 13-19.

Pratama, Y., A., Sopandi., W \& Hidayah, Y. (2019). RADEC Learning Model (Read, Answer, Discuss, Explain And Create): The Importance of Building Critical Thinking Skills In Indonesian Context. International Journal for Educational and Vocational Studies, 2(1), 109-115.

Pratama, Y. A., Sopandi, W., \& Hidayah, Y. (2019). Model Pembelajaran Radec (Read-Answer-DiscussExplain And Create): Pentingnya Membangun Keterampilan Berpikir Kritis Dalam Konteks Keindonesiaan. Indonesian Journal of Learning Education and Counseling, 2(1), 1-8. https://doi.org/10.31960/ijolec.v2i1.99

Rusman. (2015). Model Pembelajaran: Mengembangkan Profesionalisme Guru. Jakarta: Rajawali Pers.

Sopandi, W., \& Handayani, H. (2019). The Impact of Workshop on Implementation of Read-Answer-DiscussExplain-And-Create (RADEC) Learning Model on Pedagogic Competency of Elementary School Teachers. 178(ICoIE 2018), 7-11. https://doi.org/10.2991/icoie-18.2019.3

Sugiyono. (2015). Metode Penelitian Pendidikan Pendekatan Kuantitatif, Kualitatif, $R \& D$. Bandung: Alfabeta.

Wanelly, W., \& Fitria, Y. (2019). Pengaruh Model Pembelajaran Integrated dan Keterampilan Berpikir Kritis terhadap Hasil Belajar IPA. Jurnal Basicedu, 3(1), 180-186. https://doi.org/10.31004/basicedu.v3i1.107

Widyastono, H. (2015). Pengembangan Kurikulum di Era Otonomi Daeah. Jakarta: Bumi Aksara. 